\title{
Modified coconut coir to remove hexavalent chromium from aqueous solution
}

\author{
N. Ahmed*, M. N. Islam, M. Y. Hossain, A. K. M. L. Rahman and A. Sultana \\ Department of Chemistry, Jagannath University, Dhaka-1100, Bangladesh
}

Received: 10 January 2018

Revised: 01 February 2018

Accepted: 23 May 2018

DOI: https://doi.org/10.3329/bjsir.v54i1.40735

\begin{abstract}
Hexavalent chromium (Cr(VI)) was removed from aqueous solution by adsorption using chemically modified lignin-rich low-cost coconut coir. The equilibrium time, adsorption isotherm and adsorption kinetics at certain conditions such as $\mathrm{pH}$, particle size and the initial concentration of adsorbate were investigated. The coconut coir was modified by sodium chlorite for adsorption studies. The scanning electron microscopic image depicted the morphology of SCM-CC of different particle sizes whereas the elemental composition of this sort of bioadsorbent was determined by using energy dispersive spectroscopic data. Fourier transform infrared (FTIR) spectrometry analysis indicated that the carbonyl $(\mathrm{C}=\mathrm{O})$ groups and hydroxy $(\mathrm{O}-\mathrm{H})$ groups from the lignin structure in coconut coir may be involved in the mechanism of $\mathrm{Cr}(\mathrm{VI})$ adsorption. The maximum $\mathrm{Cr}(\mathrm{VI})$ adsorption capacity of sodium chlorite modified coconut coir (SCM-CC) was found to be $28.03 \mathrm{mg}$ $\mathrm{Cr}(\mathrm{VI}) \mathrm{g}^{-1} \mathrm{SCM}-\mathrm{CC}$ at $\mathrm{pH} 2.00$ for the particle size of $75-100 \mu \mathrm{m}$ with the dose of $7.5 \mathrm{~g} / \mathrm{L}$. The equilibrium was established within three hours resulting in the maximum removal $(99.92 \%)$ of chromium. Freundlich isotherm was better fitted than Langmuir isotherm at $\mathrm{pH} 2.00$ on the basis of the regression coefficient $\left(\mathrm{R}^{2}\right)$. The kinetic data well-fitted with Ho's pseudo second order kinetics. The SCM-CC can be treated as an excellent adsorbent for the remediation of chromium toxicity.
\end{abstract}

Keywords: Coconut coir; sodium chlorite; chromium (VI); adsorption; isotherm; removal

\section{Introduction}

The heavy metals (e.g., As, $\mathrm{Pb}, \mathrm{Cd}, \mathrm{Cr}$ etc.) induce toxic impacts on all the living entities including humans if they are thrown to the water without proper treatment. Among the three common stable valence states: $0,3+$ and $6+$ the hexavalent chromium ( $\mathrm{Cr}(\mathrm{VI})$ ) has been found to impose the greatest threat to the living organism. It can naturally be found in the crust of the earth, although it is primarily emitted to the environment as a result of anthropogenic activities. The researchers (Mukherjee, 1998; Kotas and Stasicka, 2000; Ellis et al., 2002; Paustenbach et al., 2003; Krystek and Ritsema, 2007) have extensively reviewed the occurrence and distribution of chromium in the environment. Serious health problem is caused by the uncontrolled release of $\mathrm{Cr}(\mathrm{VI})$ in the environment without appropriate treatment. It causes respiratory, skin (Bruynzeel et al., 1988), carcinogenic (Dayan and Paine, 2001), renal (Kirschbaum et al., 1981), hepatic (Pascale et al., 1952), gastrointestinal, cardiovascular (Loubieres et al., 1999), hematological, genotoxic and mutagenic effects on human body.

Several studies have been carried out so far in order to find effective adsorbent to mitigate chromium from polluted water. Raji and Anirudhan (1998) used batch process for removing Cr(VI) by polyacrylamide-grafted sawdust and studied kinetics and thermodynamics. The process was found to be exothermic with a maximum adsorption of $91.0 \%$ at $30^{\circ} \mathrm{C}$ for an initial concentration of $100 \mathrm{mg} / \mathrm{L}$ at $\mathrm{pH} 3.00$. Coconut coir was also used as bioadsorbent in order to remove $\mathrm{Cr}(\mathrm{VI})$ from laboratory waste water (Gonzalez et al., 2008). The research revealed that about $17 \%$ of $\mathrm{Cr}$ had been removed from sulphochromic waste water solution by dried coconut coir whereas $72 \%$ of $\mathrm{Cr}$ was removed by hydrated coconut coir.

\footnotetext{
*Corresponding author e-mail: nafees@chem.jnu.ac.bd
} 
Research for investigating the biosorption of chromium from industrial waste water was also done of by using pistachio hull waste biomass (Moussavi and Barikbin, 2010). Inorganic mineral as well as activated carbon are also being used for the removal of chromium from waste water. Wanees et al. (2012) investigated the adsorption potential of activated carbon and bentonite for the removal of $\mathrm{Cr}(\mathrm{VI})$ ions from waste water. They conducted comparative study of the adsorption of $\mathrm{Cr}(\mathrm{VI})$ on these two surfaces at different conditions, i.e., contact time, adsorbent dose, temperature, $\mathrm{pH}$ etc. through thermodynamic and kinetic study. Bentonite was found to be more effective adsorbent in removing $\mathrm{Cr}(\mathrm{VI})$. In comparison with the adsorbents (carbon and bentonite) mentioned above, the adsorbent (sodium chlorite treated coconut coir (SCM-CC)) used in this study is more cost effective and easily available in order to carry out the present work.

In the present study raw coconut coir was modified by sodium chlorite to enhance the adsorption capacity which was not good enough in the previous study for the removal of $\mathrm{Cr}(\mathrm{VI})$ by this sort of bioadsorbent (Gonzalez et al., 2008). Besides, the adsorption of Cr(VI) on SCM-CC was also investigated under several experimental conditions such as contact time, particle size, $\mathrm{pH}$ and the initial concentration of adsorbate solution. The major goal has been the optimization of conditions of adsorption to efficiently remove $\mathrm{Cr}(\mathrm{VI})$ from aqueous solution

\section{Materials and methods}

\section{Chemicals and instrumentation}

Analytical grade potassium dichromate $\left(\mathrm{K}_{2} \mathrm{Cr}_{2} \mathrm{O}_{7}\right)$ (Scharlau Chemicals, Spain) was used as the source of $\mathrm{Cr}(\mathrm{VI})$ in this research work. Coconut coir $(\mathrm{CC})$ collected from the local market was treated by sodium chlorite $\left(80 \% \mathrm{NaClO}_{2}\right)$ (BDH Laboratory Supplier, England) for using as adsorbent for this experiment.

Single beam UV-visible recording spectrophotometer (OPTIZEN POP, Korea) was used to analyze $\mathrm{Cr}(\mathrm{VI})$. IR spectra of SCT-CC were recorded before and after adsorption using a FTIR spectrophotometer (Model: Frontier FT-NIR/MIR, Perkin Elmer, USA).

\section{Processing of coconut coir}

Fibrous coir purchased from the local market was washed with tape water for several times to remove dust and pigments and was again washed with distilled water for three times and was air-dried followed by drying in oven at $110^{\circ} \mathrm{C}$ and the resulting crispy materials were grinded. This untreated coconut coir (UCC) was used for the further treatment.

\section{Modification of coconut coir}

According to the matrix designed by Box-Behnken experimental design (Liu et al., 2012), the previously obtained UCC was stirred with $6.2 \mathrm{~g}$ of sodium chlorite in the presence of $9.5 \mathrm{~mL}$ of acetic acid for about $60 \mathrm{~min}$ at 150-200 rpm with designed reaction temperature $90^{\circ} \mathrm{C}$. The treated $\mathrm{CC}$ was washed with distilled water until the filtrate had reached $\mathrm{pH} 6-7$, then dried at $70^{\circ} \mathrm{C}$ to a constant weight, screened through sieve and stored in desiccators for further use. The modified coconut coir thus obtained was termed as sodium chlorite modified coconut coir (SCM-CC).

\section{Batch adsorption studies}

About $0.3 \mathrm{~g}$ of SCM-CC (particle size of $75-100 \mu \mathrm{m}$ measured by using metallic sieve) was charged in reagent bottles containing $\mathrm{Cr}(\mathrm{VI})$ solution of concentration about $200 \mathrm{ppm}$ (prepared from stock solution of $1000 \mathrm{ppm}$ ) at pH $2 \pm 0.02$. These bottles were shaken in the mechanical shaker at room temperature $\left(\approx 28.0 \pm 0.5^{\circ} \mathrm{C}\right)$. After a particular interval of time the reagent bottles were withdrawn from the shaker. The supernatant was centrifuged to obtain a clear solution. The experiment was repeated for the SCM-CC of particle size 100-200 and 200-300 m.

\section{Analysis and characterization of surface}

Chromium concentration in the solution was determined by using UV-visible spectrophotometer. The $\lambda \max$ of the solution was found to be within $360-370 \mathrm{~nm}$ at all the $\mathrm{pH}$ values under observation. Adsorption kinetics was investigated using three different particle sizes, 75-100, $100-200$ and $200-300 \mu \mathrm{m}$ of SCM-CC at room temperature $\left(28.0 \pm 0.5^{\circ} \mathrm{C}\right)$. 
The surface of the SCM-CC of different particles sizes before and after adsorption of $\mathrm{Cr}(\mathrm{VI})$ was characterized by FTIR (Frontier FT-NIR/MIR (Perkin Elmer, USA)) spectroscopy in order to find out whether any shifting of IR peak due to the interaction of $\mathrm{Cr}(\mathrm{VI})$ with SCM-CC occurred or not. The scanning electron microscopic (SEM) images were recorded to investigate the morphology of the surface by using a JSM-5600LV SEM instrument (JEOL, USA) with gold film. The samples were coated with platinum to avoid charging. The elemental composition of the bioadsorbent (SCM-CC) was determined by utilizing energy dispersive spectroscopy (EDS).

\section{Results and discussion}

\section{Characterization of surface}

\section{FTIR analysis}

FTIR spectra are commonly used to confirm the presence of functional groups on the surface of bioadsorbent and thus the FTIR spectra of bare SCM-CC and $\mathrm{Cr}(\mathrm{VI})$ adsorbed SCM-CC at different particle sizes were investigated and are shown in Fig. 1. The band for the stretching vibration of $-\mathrm{OH}$ in cellulose of CC was found to become broader at 3439.7 $\mathrm{cm}^{-1}$ in the case of bare SCM-CC, which might be due to the formation of hydrogen bond after treatment. This broader band became comparatively sharper after the adsorption of $\mathrm{Cr}(\mathrm{VI})$ onto SCM-CC of different particle sizes.

However, the FTIR spectra of $-\mathrm{OH}$ group for $\mathrm{Cr}(\mathrm{VI})$ adsorbed SCM-CC of different particle seizes were found to be quite similar. It indicates that the chemical interaction between the SCM-CC and $\mathrm{Cr}(\mathrm{VI})$ is not affected by changing the particle size of the surface. Another band at $1612.8 \mathrm{~cm}^{-1}$ indicates the existence of $\mathrm{C}=\mathrm{C}$ in bare SCM-CC. This band becomes more intense after the adsorption of $\mathrm{Cr}(\mathrm{VI})$ onto SCM-CC.

\section{SEM analysis}

The surface morphology of SCM-CC with different particle sizes was observed executing SEM analysis. The tube like coir was found in all the cases (Fig. 2 (a-c)). Moreover, the clear porous structure was noticed after the adsorption of $\mathrm{Cr}(\mathrm{VI})$ onto SCM-CC of different particle sizes. The porosity evolved in the coir matrix was found to differ for different

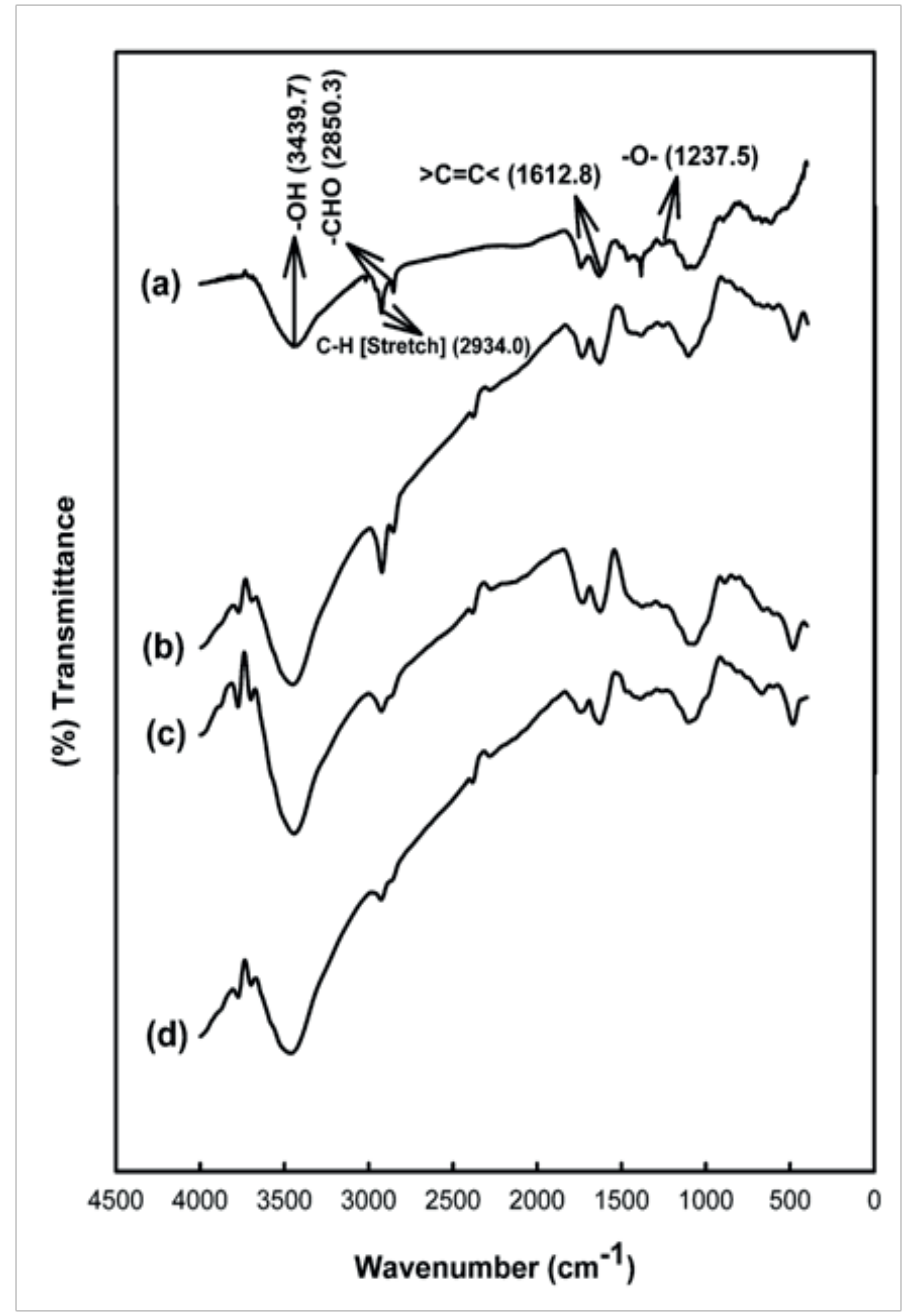

Fig. 1. FTIR spectra of (a) bare SCM-CC and Cr(VI)adsorbed SCM-CC on (b) $75-100 \mu \mathrm{m}$, (c) $100-200 \mu \mathrm{m}$ and (d) 200-300 $\mu \mathrm{m}$ of SCM-CC

particle sizes. The result showed the dissimilarity to that reported before in the case of coconut coir pith (Sheel et al., 2016). Scanning electron microscopic (SEM) photographs revealed the porosity and adsorptive nature of $\mathrm{CC}$.

Due to the evolution of porous site the surface of SCM-CC became more conducive to $\mathrm{Cr}$ (VI) to adsorb onto it rather than raw coconut coir.

\section{Adsorption behaviour}

\section{Equilibrium time}

The $q_{t}$ (the amount of $\mathrm{Cr}(\mathrm{VI})$ adsorbed) vs. time curve (Fig. 3) for the adsorption of $\mathrm{Cr}(\mathrm{VI})$ on SCM-CC was found to be 


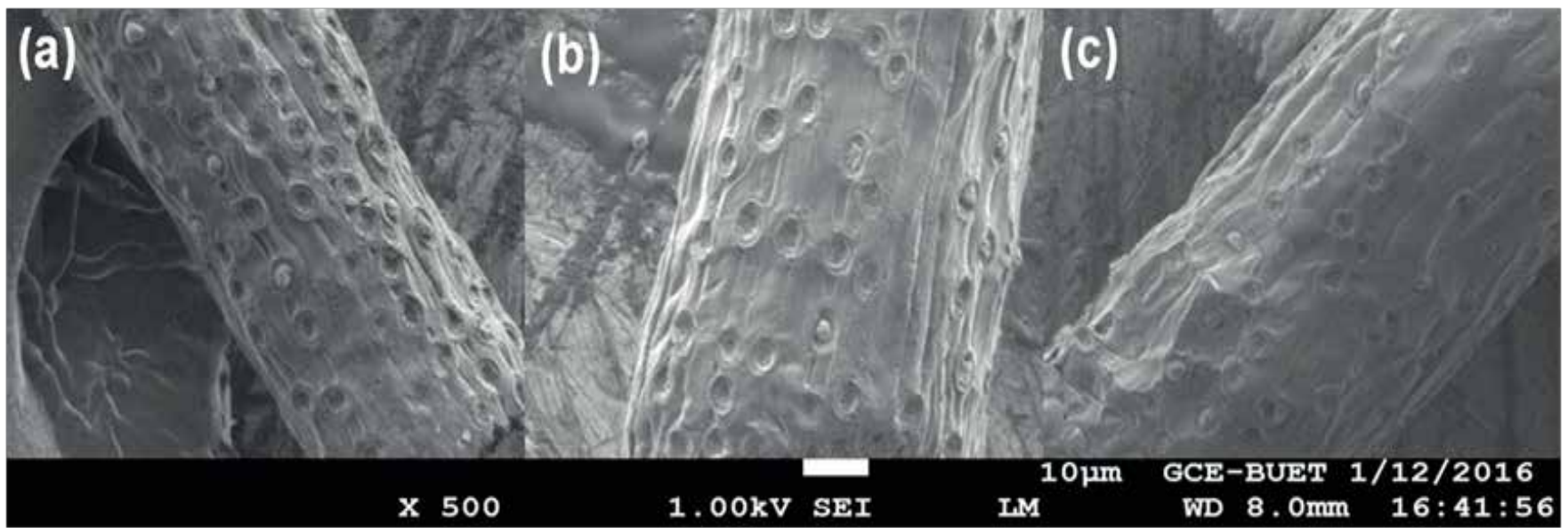

Fig. 2. Scanning electron microscopic (SEM) images for different particle sizes of SCM-CC, (a) $75-100 \mu \mathrm{m}$, (b) $100-200 \mu \mathrm{m}$ and (c) 200-300 $\mu \mathrm{m}$ at $500 \times$ magnification

similar with the usual curves. After the quick increase of the amount adsorbed at the beginning, the adsorption of $\mathrm{Cr}(\mathrm{VI})$ on SCM-CC reached the equilibrium within $3 \mathrm{~h}$ at smaller particle sizes (i.e., 75-100 \& 100-200 $\mu \mathrm{m}$ ).

However, at larger particle size (such as 200-300 ? $\mu \mathrm{m}$ ) the system took about $4 \mathrm{~h}$ to attain the equilibrium. Two different observations may be pointed out here. In one case, the initial increase of the amount of $\mathrm{Cr}$ (VI) adsorbed onto SCM-CC was sharp to eventually attain the steady value. Gradual increase in the curve followed by the slow attainment of the steady value was observed in the other case.

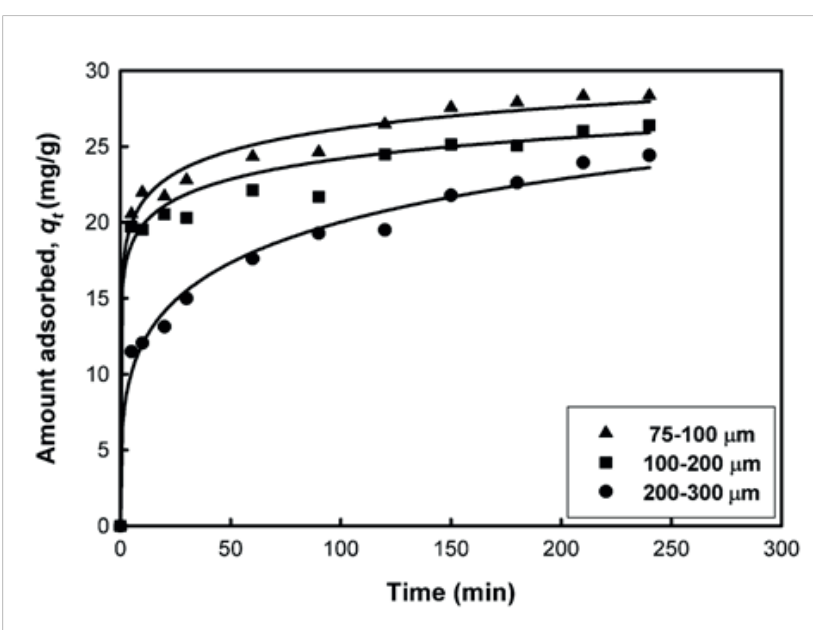

Fig. 3. Variation of the amount of $\mathrm{Cr}(\mathrm{VI})$ adsorbed on SCM-CC of different particle sizes as a function of time at $\mathrm{pH} 2.00$ at room temperature $\left(28.0 \pm 0.5^{\circ} \mathrm{C}\right)$

\section{Effect of particle size}

The adsorption capacity of SCM-CC against Cr(VI) was found to be influenced by the particle size of SCM-CC (Fig. 4). The amount of Cr(VI) adsorbed on SCM-CC was observed to be the highest (28.03 $\mathrm{mg} / \mathrm{g}$ ) for the particle size of $75-100 ? \mu \mathrm{m}$ and the lowest $(23.66 \mathrm{mg} / \mathrm{g})$ for that of $200-300 ? \mu \mathrm{m}$. The percent removal of $\mathrm{Cr}(\mathrm{VI})$ from aqueous solution was found to be maximum $99.92 \%$ at lower $\mathrm{pH}$ by using SCM-CC of particle size 75-100 $\mu \mathrm{m}$. The particle size is inversely correlated with the external surface area per $g$ of adsorbent. Smaller the particle size higher will be the value of external surface area or vice versa. High value of external surface area is attributed to the high adsorption capacity of the adsorbent. Therefore, the SCM-CC of smaller size $(75-100 \mu \mathrm{m})$ exhibited the maximum removal of Cr(VI) compared with that of larger size (100-200 or 200-300 Cm). This is in a good agreement with the observation by Panda et al., 2011.

\section{Effect of $p H$}

The $\mathrm{pH}$ has the pronounced effect on surface phenomena. Adsorption of heavy metal is definitely dependent on $\mathrm{pH}$ of the adsorbate solution. With a view to determining the suitable $\mathrm{pH}$ for adsorption, tests were carried out taking initial concentration (200 ppm) of potassium dichromate. In present research it was also proved experimentally that the change in $\mathrm{pH}$ from lower to higher (2.00 to 7.00$)$ caused the decrease in 


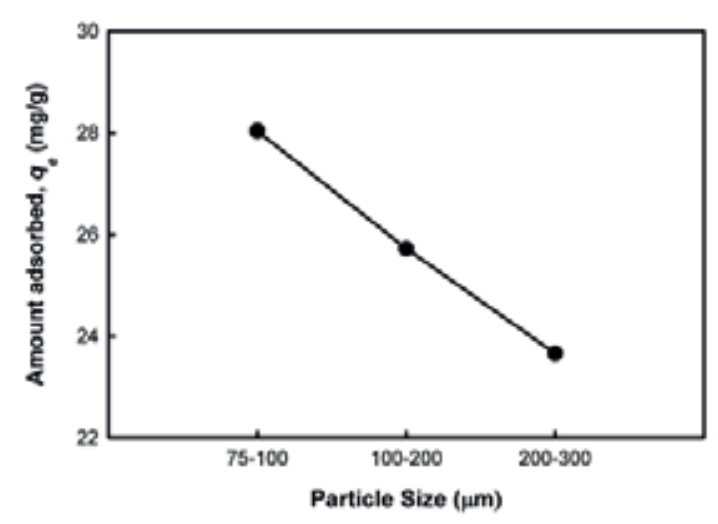

Fig. 4. Variation of the equilibrium amount of $\mathrm{Cr}$ (VI) adsorbed per gram of SCM-CC with particle size at 2.00 at room temperature $\left(28 \pm 0.5^{\circ} \mathrm{C}\right)$

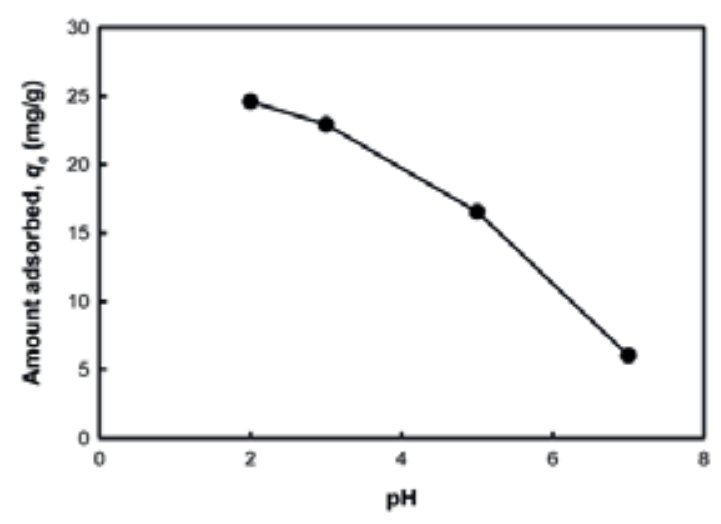

Fig. 5. Effect of pH on $\mathrm{Cr}$ (VI) adsorption on SCM-CC at room temperature $\left(28 \pm 0.5^{\circ} \mathrm{C}\right)$.

the effective removal of $\mathrm{Cr}(\mathrm{VI})$ by adsorption. The amount adsorbed $\left(q_{e}\right)$ of $\mathrm{Cr}(\mathrm{VI})$ onto SCM-CC was found to be the lowest at high $\mathrm{pH}$ value ( $\mathrm{pH} 7.00)$ whereas low $\mathrm{pH}(\mathrm{pH} 2.00)$ of the system exhibited the highest adsorption of chromium. The variation of equilibrium adsorbed amount $\left(q_{e}\right)$ for SCM-CC with $\mathrm{pH}$ was shown in Fig. 5. Since dichromate is a composite anion, when the $\mathrm{pH}$ was increased surface become negative and because of this there was a repulsive force generated between the adsorbate and the surface. But as the $\mathrm{pH}$ was decreased to lower values, the surface became positively charged and negatively charged dichromate ion experienced the electrostatic force of attraction towards the surface to increase the amount of adsorbed species. This agrees well with Suksabye et al. (2007). The Cr(VI) adsorption efficiency of activated carbon based on coconut shell was reported to decrease with the increase of the system $\mathrm{pH}$ values from 2 to 10 . Islam et al. (2016) showed the effect of $\mathrm{pH}$ on the adsorption kinetics of $\mathrm{Cr}(\mathrm{VI})$ on sodium chlorite treated coconut coir. In that case the rate of adsorption was shown to decrease as the $\mathrm{pH}$ was tuned from lower to higher values.

\section{Effect of initial concentration}

The varying initial concentration of dichromate was found to have marked effect on the equilibrium amount of adsorbed $\mathrm{Cr}(\mathrm{VI})$. Experiments for the dye $\mathrm{Cr}$ (VI) were carried out by selecting a concentration range of 20-200 ppm with an adsorbent dosage of $0.3 \mathrm{~g}$ for SCM-CC at room temperature $\left(28 \pm 0.5 ?^{\circ} \mathrm{C}\right)$. The experimental results showed that an increase in the concentration caused an increase in the amount of the $\mathrm{Cr}(\mathrm{VI})$ adsorbed. This increase in adsorption of $\mathrm{Cr}(\mathrm{VI})$ with concentration is attributed to the retardation of resistance toward chromium uptake, which increases the diffusion of dichromate (Fig. 6). The uptake of $\mathrm{Cr}(\mathrm{VI})$ onto SCM-CC at $\mathrm{pH} 2.00$ was found to increase further if the initial concentration $\mathrm{Cr}(\mathrm{VI})$ would have been increased much. On the other hand, at $\mathrm{pH}$ 3.00 the initial concentration of $\mathrm{Cr}(\mathrm{VI})$ was observed to have no effect on the amount adsorbed up to $100 \mathrm{ppm}$. However, the uptake of chromium at $\mathrm{pH} 3.00$ started to increase after $100 \mathrm{ppm}$ and remained constant at the proximity of $200 \mathrm{ppm}$.

This can be compared with the results obtained from the removal of hexavalent chromium-contaminated wastewater using activated carbon and bentonite (Wanees et al., 2012) where the uptake of $\mathrm{Cr}^{6+}$ was found to increase with the initial concentration for both the adsorbents. In the present case, the relation between the amount adsorbed and the initial concentration followed the usual pattern in more acidic condition whereas the uptake of chromium was found to be

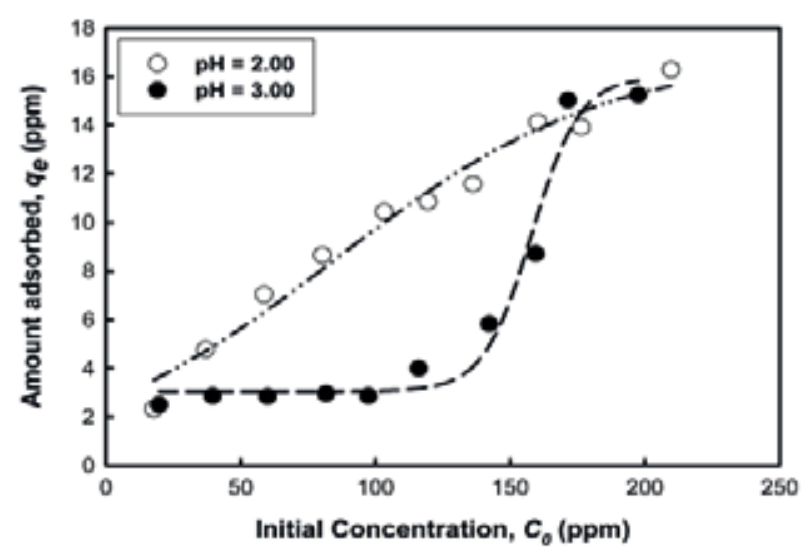

Fig. 6. Amount of Cr(VI) adsorbed on SCM-CC with varying initial concentration of dichromate at different $\mathrm{pH}$ values at room temperature $\left(28 \pm 0.5^{\circ} \mathrm{C}\right)$ 
independent on $\mathrm{pH}$ to a certain range of initial concentration of dichromate at less acidic medium. This trend of chromium uptake pattern remained same up to the concentration of 200 ppm after a quick rise in the range of 100 and 200 ppm.

\section{EDS analysis}

EDS analysis was performed to determine the elemental composition of the biosorbents after metal ion adsorption. Carbon and oxygen are the major constituents in the biosorbents. Their features can be observed at 0.277 and $0.525 \mathrm{keV}$, respectively. As the surface of $\mathrm{CC}$ was modified by sodium chlorite, then the features of sodium and chlorine appeared at 1.041 and $2.621 \mathrm{keV}$ respectively. Fig. 11 presents the EDS spectrum of SCM-CC following $\mathrm{Cr}$ (VI) adsorption, as an example. As shown in Fig. 7, new peaks appeared at $5.411 \mathrm{keV}$ represents the feature of $\mathrm{Cr}$. Overall, the appearance of EDS feature of $\mathrm{Cr}$ on the surface of biosorbents entails the ability of SCM-CC for metal ions binding.

\section{Adsorption isotherm}

The adsorption isotherm refers to the plot of the amount adsorbed against equilibrium concentration at constant temperature. The most favored approach to an investigation of the adsorption mechanism is a study of the isotherm. The implication of the adsorption isotherms in adsorption mechanisms is based on few aspects such as the shape of isotherm, the significance of the plateau in many isotherms, the orientation of the adsorbed molecules. The data of the adsorption isotherms obtained for the adsorption of $\mathrm{Cr}(\mathrm{VI})$ onto SCM-CC at $\mathrm{pH} 2.00$ and 3.00 at room temperature $(28 \pm$ $0.5^{\circ} \mathrm{C}$ ) were examined whether they are fitted to the Langmuir or Freundlich isotherms to understand the adsorption behavior.

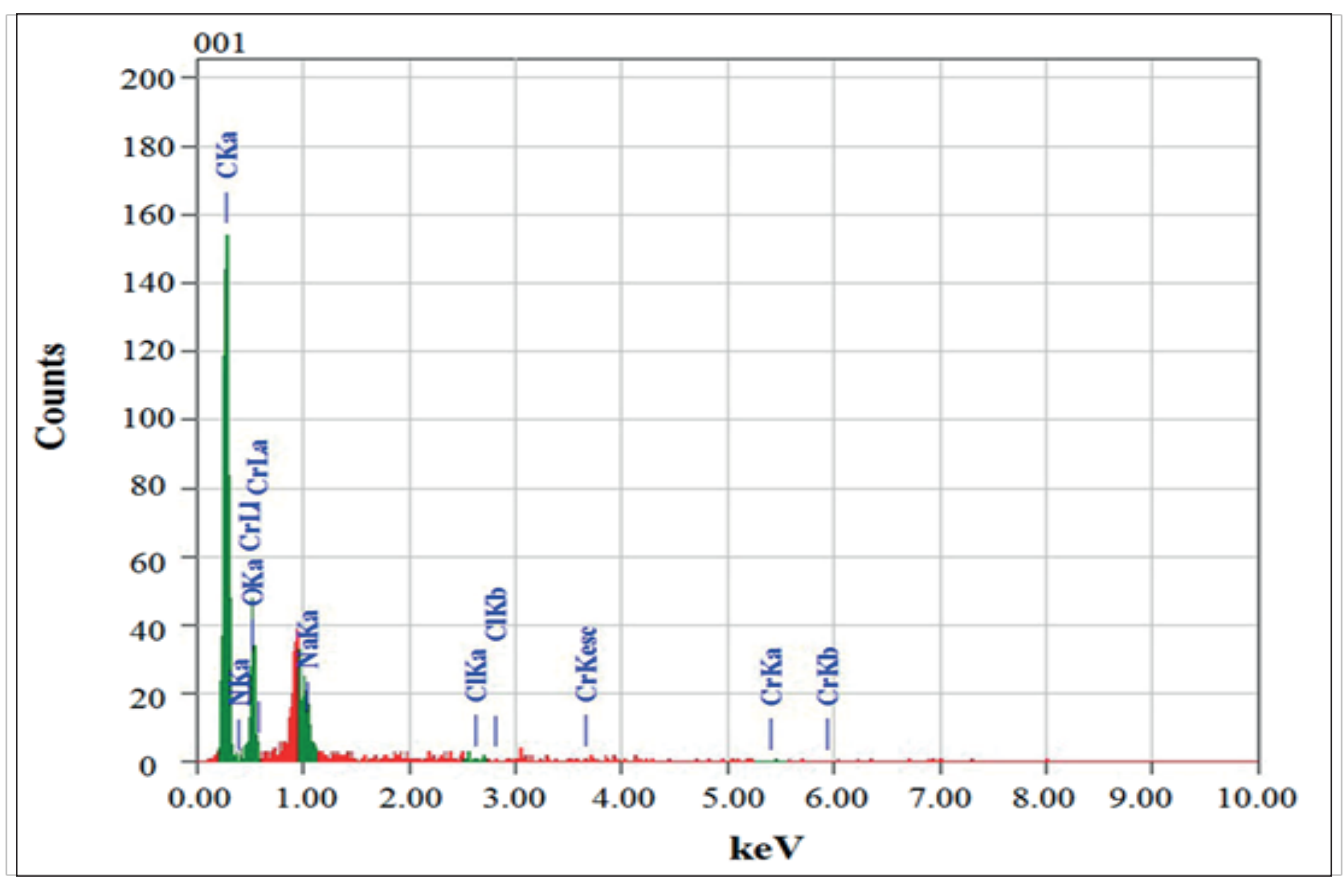

Fig. 7. Energy dispersive spectrum (EDS) of SCM-CC after interaction with Cr(VI) 


\section{Langmuir isotherm}

The Langmuir Isotherm equation:

$$
\begin{aligned}
& x / m=\mathrm{a}_{\mathrm{e}} /\left(1+\mathrm{b} C_{\mathrm{e}}\right) \\
& \therefore C_{\mathrm{e}} / x / m=1 / \mathrm{kK}_{\mathrm{eq}}+C_{\mathrm{e}} / \mathrm{k} \\
& \text { or, } C_{\mathrm{e}} / q_{\mathrm{e}}=1 / q_{\mathrm{m}} \mathrm{K}_{\mathrm{eq}}+C_{\mathrm{e}} / q_{\mathrm{m}}
\end{aligned}
$$

\section{Freundlich isotherm}

The Freundlich model was applied to calculate the adsorption data of $\mathrm{CV}$, as per the given relation:

$x / m=\mathrm{K}_{\mathrm{F}} C_{\mathrm{e}}{ }^{1 / n}$

or $\log (x / m)=\log \mathrm{K}_{\mathrm{F}}+1 / n \log C_{\mathrm{e}}$

The adsorption isotherm found experimentally was fitted relatively more precise to Freundlich than to Langmuir isotherm for the experiment carried out with $\mathrm{SCM}-\mathrm{CC}$ at $\mathrm{pH}$ 2.00 and 3.00. In the case of $\mathrm{pH} 2.00$ the value of correlation coefficient, $\mathrm{R}^{2}$, was only 0.946 (Fig. 8) for fitting with Langmuir equation whereas the isotherm was precisely Freundlich type depicted in Fig. 8. Here, the value of correlation coefficient, $\mathrm{R}^{2}$, was found to be 0.976 (Fig. 9) for Freundlich isotherm. On the other hand, the adsorption isotherm was neither found to fit with Langmuir nor Freundlich isotherms (Fig. 8 and Fig. 9) at $\mathrm{pH}$ 3.00. In this case $\mathrm{R}^{2}$ value was found to be 0.192 (Fig. 8) and 0.194 (Fig. 9) for fitting with Langmuir and Freundlich isotherm respectively.

\section{Adsorption kinetics}

The data obtained from the estimation of equilibrium time for the adsorption of $\mathrm{Cr}(\mathrm{VI})$ on SCM-CC of different

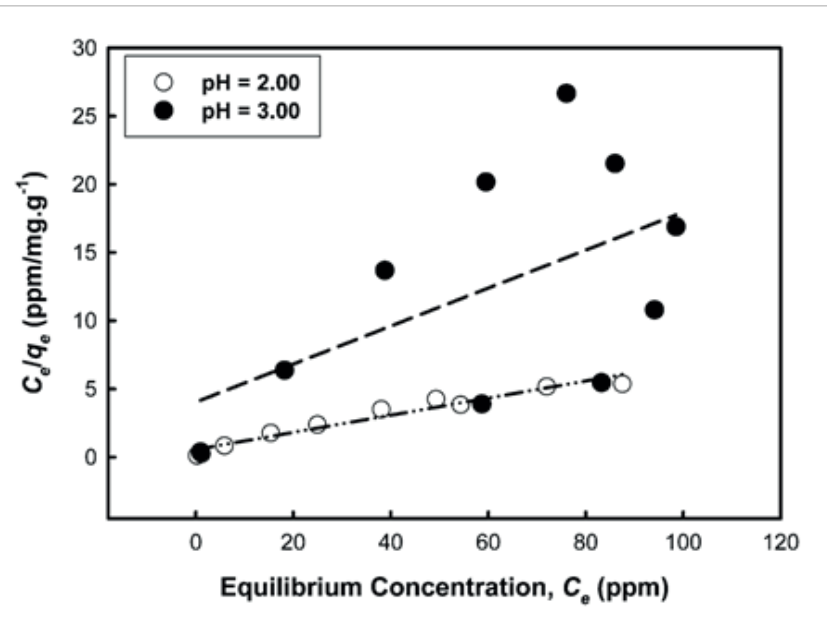

Fig. 8. $\log \mathrm{C}_{e} / q_{e}$ vs. $C_{e}$ for fitting with Langmuir isotherm for the adsorption of Cr(VI) on SCM-CC and SCT-CC at pH $2.00\left(R^{2}=0.946\right)$ and $3.00\left(R^{2}=0.192\right)$ at room temperature $\left(28 \pm 0.5^{\circ} \mathrm{C}\right)$.

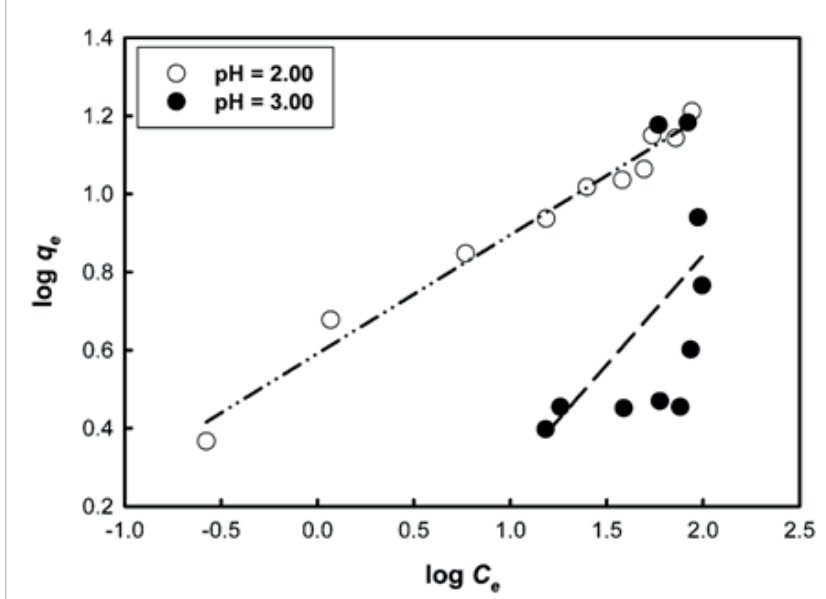

Fig. 9. $\log \mathrm{q}_{e} \mathrm{vs.} \log \mathrm{C}_{e}$ for fitting with Freundlich Isotherm for the adsorption of $\mathrm{Cr}(\mathrm{VI})$ on SCM-CC and SCT-CC at pH 2.00 $\left(R^{2}=0.976\right)$ and $3.00\left(R^{2}=0.194\right)$

Table I. Langmuir and Freundlich coefficients for the adsorption of Cr(VI) on SCM-CC at pH 2.00 and 3.00 and at the temperature $\left(28 \pm 0.5^{\circ} \mathrm{C}\right)$

\begin{tabular}{ccccccc}
\hline $\mathrm{pH}$ & \multicolumn{3}{c}{ Langmuir Coefficients } & \multicolumn{3}{c}{ Freundlich Coefficients } \\
\cline { 2 - 6 } & $\begin{array}{c}\mathrm{q}_{\mathrm{m}} \\
(\mathrm{mg} / \mathrm{g})\end{array}$ & $\mathrm{K}_{\mathrm{eq}}(\mathrm{L} / \mathrm{mg})$ & $\mathrm{R}^{2}$ & $\mathrm{~K}_{\mathrm{F}}(\mathrm{L} / \mathrm{g})$ & $n$ & $\mathrm{R}^{2}$ \\
\hline 2.00 & 15.92 & 8.94 & 0.946 & 3.90 & 3.29 & 0.976 \\
3.00 & 7.18 & 29.01 & 0.192 & 1.90 & 1.78 & 0.194 \\
\hline
\end{tabular}


Table II. Pseudo first order and pseudo second order kinetic parameters for the adsorption of Cr(VI) onto SCM-CC of different particle sizes

\begin{tabular}{|c|c|c|c|c|c|}
\hline \multirow{2}{*}{$\begin{array}{l}\text { Particle size } \\
\qquad(\not \mathrm{m})\end{array}$} & \multirow[t]{2}{*}{$q_{e}(\mathrm{mg} / \mathrm{g})$} & \multicolumn{2}{|c|}{ Pseudo -First -order kinetic model } & \multicolumn{2}{|c|}{ Pseudo-Second-order kinetic mode } \\
\hline & & $k_{l}\left(\min ^{-1}\right)$ & $\mathrm{R}^{2}$ & $k_{2}(\mathrm{~g} /(\operatorname{mg} \min ))$ & $\mathrm{R}^{2}$ \\
\hline $75-100$ & 191.20 & $7.71 \times 10^{-5}$ & 0.926 & $4.66 \times 10^{-2}$ & 0.998 \\
\hline $100-200$ & 203.38 & $6.62 \times 10^{-5}$ & 0.942 & $4.48 \times 10^{-2}$ & 0.995 \\
\hline 200-300 & 170.92 & $10.00 \times 10^{-5}$ & 0.942 & $2.06 \times 10^{-2}$ & 0.987 \\
\hline
\end{tabular}

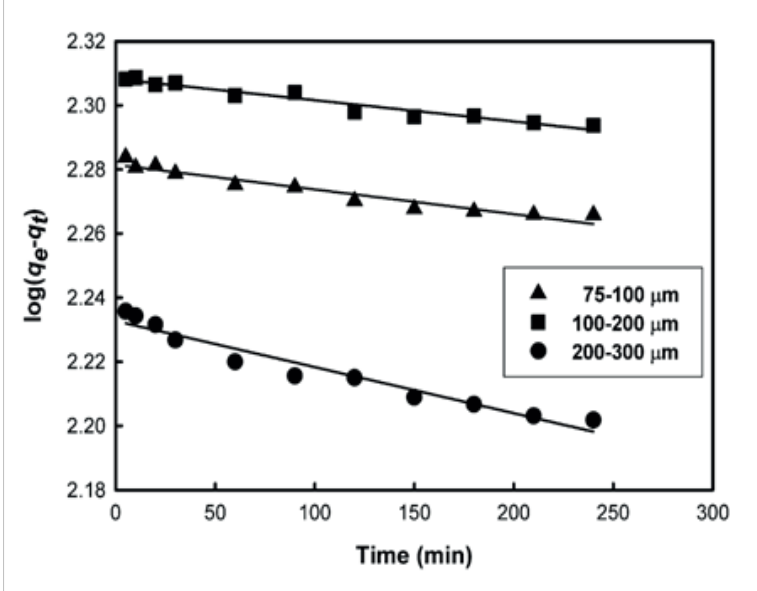

Fig. 10. $\log \left(q_{e}-q_{t}\right)$ vs. time for fitting with Lagergren equation of first order kinetics for adsorption of $\mathrm{Cr}$ (VI) on SCM-CC of different particle sizes, $75-100 \mu \mathrm{m}$ $\left(R^{2}=0.926\right), 100-200 \mu m\left(R^{2}=0.942\right)$ and $200-300 \mu m$ $\left(R^{2}=0.942\right)$ at $\mathrm{pH} 2.00$.

particle sizes, $75-100 ? \mathrm{~m}, 100-200 ? \mathrm{~m}$ and $200-300 ? \mathrm{~m}$ were fitted in both Lagergren first order kinetic equation and Ho's pseudo-second order kinetic equation. The data for first and second order kinetics at different $\mathrm{pH}$ were depicted in the Fig. 10 and Fig. 11 respectively. The values of correlation coefficient, $\mathrm{R}^{2}$, indicated in the Table 2 revealed that the adsorption kinetics of $\mathrm{Cr}(\mathrm{VI})$ onto SCM-CC mostly follows Ho's pseudo second order kinetics model for all particle sizes.

The kinetic model fitted with Lagergren first order,

$\log \left(q_{e}-q_{t}\right)=\log q_{e}-k_{l} t$

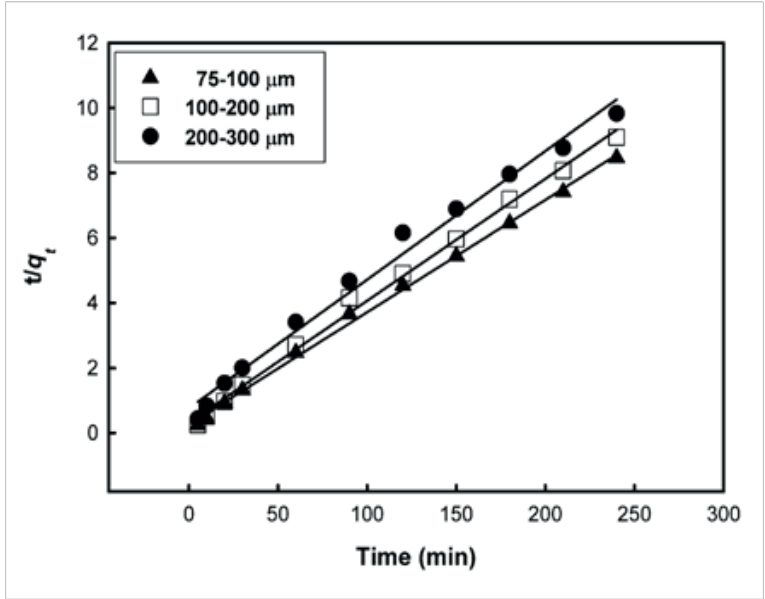

Fig. 11. $t / q t$ vs. time for fitting with Ho's equation of pseudo second order kinetics for adsorption of $\mathrm{Cr}$ (VI) on SCM-CC of different particle sizes, $75-100 \mu \mathrm{m}$ $\left(R^{2}=0.998\right), 100-200 \mu m\left(R^{2}=0.995\right)$ and $200-300 \mu m$ $\left(R^{2}=0.987\right)$ at $\mathrm{pH} 2.00$

and Ho's pseudo-second order kinetic equation as follows:

$t / q_{t}=1 / k_{2} q_{e}^{2}+t / q_{e}$

In the above equation $q_{e}$ and $q_{t}$ denote the amounts adsorbed at equilibrium and at any time $t$, respectively, and $k_{1}$ and $k_{2}$ are the first order and second-order rate constants respectively.

\section{Conclusions}

Cr(VI) adsorps on SCM-CCT at pH 5.00 and 7.00 and the equilibrium is attained rapidly. The lower value of $\mathrm{pH}$ (2.00 and 3.00) facilitated the adsorption on 
SCT-CC. The adsorption kinetics was found to be influenced by the action of the $\mathrm{pH}$ of the solution. The high value of the rate of adsorption was observed at $\mathrm{pH}$ 2.00 and 3.00, which fell drastically when the $\mathrm{pH}$ was increased to 5.00 and 7.00. The kinetic data indicated that the interaction between the $\mathrm{Cr}(\mathrm{VI})\left(\mathrm{Cr}_{2} \mathrm{O}_{7}{ }^{2-}\right)$ and SCM-CC is fully electrostatic. Because of the electrostatic force of attraction between negatively charged adsorbate species and positively charged adsorbent enhanced the rate of adsorption at lower $\mathrm{pH}$ whereas the neutral $\mathrm{pH}$ showed very much weaker interaction between adsorbate and adsorbent.

\section{Acknowledgement}

The authors are grateful to the Material Chemistry Research Laboratory, Department of Chemistry, University of Dhaka, for providing access for FTIR analysis and the Department of Glass and Ceramic, Bangladesh University of Engineering and Technology for SEM and EDS analyses of the samples.

\section{References}

Bruynzeel DP, Hennipman G and van Ketel WG (1988), Irritant contact dermatitis and chrome-passivated metal, Contact Dermatitis 19: 175-179. doi.org/10. 1111/j.1600-0536.1988.tb02889.x

Dayan AD and Paine AJ (2001), Mechanisms of chromium toxicity, carcinogenicity and allergenicity: review of the literature from 1985 to 2000, Human \& Experimental Toxicology 20: 43951. doi.org/10.1191/096032701682693062

Ellis AS, Johnson TM and Bullen TD (2002), Chromium isotopes and the fate of $\mathrm{Cr}(\mathrm{VI})$ in the environment, Science 295: 2060-2062. DOI: 10.1126/ science. 1068368

Gonzalez MH, Araújo GCL, Pelizaro CB, Menezes EA, Lemos SG, de Sousa GB and Nogueira ARA (2008), Coconut coir as biosorbent for $\mathrm{Cr}(\mathrm{VI})$ removal from laboratory wastewater, J. Hazard. Mater. 159: 252-256. doi.org/10.1016/ j.jhazmat.2008.02.014

? Ho YS, Wase DAJ and Forster CF (1996), Kinetic studies of competitive heavy metal adsorption by sphagnum moss peat, Environmental Technology 17: 71-77. doi.org/10.1080/09593331708616362

Islam MN, Ahmed N, Hossain MY, Rahman AKML and Sultana A (2016), Effect of $\mathrm{pH}$ on the adsorption kinetics of $\mathrm{Cr}(\mathrm{VI})$ on sodium chlorite treated coconut coir, Bangladesh Journal of Scientific and Industrial Research 51(2): 95-100.doi.org/10.3329/ bjsir.v51i2.28090

Kirschbaum BB, Sprinkel FM and Oken DE (1981), Proximal tubule brush border alterations during the course of chromate nephropathy, Toxicology \& Applied Pharmacology 58: 19-30. doi.org/10. 1016/0041-008X(81)90111-3

Kota J and Stasicka Z (2000), Chromium occurrence in the environment and methods of its speciation, Environ Pollut 107: 263-283. doi.org/10. 1016/S0269-7491(99)00168-2

Krystek P and Ritsema R (2007), Monitoring of chromium species and 11 selected metals in emission and immission of airborne environment, Int J Mass Spectrom 265: 23-29. doi.org/10. 1016/j.ijms.2007.05.003

Liu Y, Wang J, Zheng Y and Wang A (2012), Adsorption of methylene blue by kapok fiber treated by sodium chlorite optimized with response surface methodology, Chemical Engineering Journal 184: 248-255. doi.org/10.1016/j.cej.2012.01.049

Loubieres Y, de Lassence A, Bernier M, Vieillard-Baron A, Schmitt JM, Page B and Jardin F (1999), Acute, fatal, oral chromic acid poisoning, Journal of Toxicology - Clinical Toxicology 37: 333-336.

Moussavi G and Barikbin B (2010), Biosorption of chromium (VI) from industrial wastewater onto pistachio hull waste biomass, Chemical Engineering Journal 162: 893-900.

Mukherjee AB (1998), Chromium in the environment of Finland, Sci Total Enviro 217: 9-19.

Panda M., Bhowal A. and Datta S. (2011) Removal of hexavalent chromium by biosorption process in rotating packed bed, Environmental Science and Technology 45: 8460-8466. 
Pascale LR, Waldstein SS, Engbring G, Dubin A and Szanto PB (1952), Chromium intoxication, with special reference to hepatic injury, Journal of the American Medical Association 149: 1385-9. doi:10.1001/jama.1952.02930320025008

Paustenbach DJ, Finley BL, Mowat FS and Kerger BD (2003), Human health risk and exposure assessment of chromium (VI) in tap water, $J$ Toxicol Environ Health, Part A 66: 1295-1339. DOI: 10.1080/ 15287390306388

Raji C and Anirudhan TS (1998), Batch Cr(VI) removal by polyacrylamide-grafted sawdust: kinetics and thermodynamics, Water Res. 32: 3772-3780.
Sheel Ratan, Indu Singh, Joy Sarkar and Naik RM (2016), The Removal of Nickel from Waste Water by Modified Coconut Coir Pith, Chemical Sciences Journal 7(3): 136-141.doi: 10.4172/ 21503494.1000136

Suksabye P, Thiravetyan P, Nakbanpote W and Chayabutra S (2007), Chromium removal from electroplating wastewater by coir pith, Journal of Hazardous Materials 141: 637-644. doi.org/10. 1016/j.jhazmat.2006.07.018

Wanees SA, Ahmed AMM, Adam MS and Mohamed MA (2012), Adsorption Studies on the Removal of $\mathrm{Cr}(\mathrm{VI})$-Contaminated Wastewater using Activated Carbon and Bentonite, Chemistry Journal 2: 95-105. 